1 A Canal-Associated Neuron cAMP signalling pathway that regulates $C$. elegans larval development

4 Jason Chien ${ }^{*}$, Fred W. Wolf ${ }^{\dagger}$, Sarah Grosche ${ }^{*, 1}$, Nebeyu Yosef ${ }^{*, 2}$, Gian

5 Garriga ${ }^{\S, 3}$ and Catarina Mörck ${ }^{*}$

6 *Department of Chemistry and Molecular Biology, University of Gothenburg,

7 Gothenburg, 405 30, Sweden

8 tSchool of Natural Sciences, University of California, Merced, CA USA 95343

9 §Department of Molecular and Cell Biology, University of California, Berkeley,

10 California, USA 94720-3204

\title{
Current addresses
}

$13{ }^{1}$ CeMM Research Center for Molecular Medicine of the Austrian Academy of

14 Sciences, Lazarettgasse 14, AKH BT 25.31090 Vienna, Austria

${ }^{2}$ Faculty of Medicine Research Program Unit Stem Cells and Metabolism, FI-

1700014 University of Helsinki, Helsinki, Finland

${ }^{3}$ Corresponding author: Department of Molecular and Cell Biology, 16 Barker

20 Hall, University of California, Berkeley, California, 94720-3204

21 email:garriga@berkeley.edu

Running title: CAN-dependent cAMP signaling 


\section{ABSTRACT}

27 Caenorhabditis elegans larval development requires the function of the two

28 Canal-Associated Neurons (CANs): killing the CANs by laser microsurgery or

29 disrupting their development by mutating the gene ceh-10 results in early

30 larval arrest. How these cells promote larval development, however, remains

31 a mystery. In screens for mutations that bypass CAN function, we identified

32 the gene kin-29, which encodes a member of the Salt-Inducible Kinase (SIK)

33 family and a component of a conserved pathway that regulates various $C$.

34 elegans phenotypes. Like kin-29 loss, gain-of-function mutations in genes that

35 may act upstream of kin-29 or growth in cyclic-AMP analogs bypassed ceh-10

36 larval arrest, suggesting that a conserved adenylyl cyclase/PKA pathway

37 inhibits KIN-29 to promote larval development and that loss of CAN function

38 results in dysregulation of KIN-29 and larval arrest. The adenylyl cyclase

39 ACY-2 mediates CAN-dependent larval development: acy-2 mutant larvae

40 arrested development with a similar phenotype to ceh-10 mutants, and the

41 arrest phenotype was suppressed by mutations in kin-29. ACY-2 is

42 predominantly expressed in the CANs, and we provide evidence that the acy-

432 functions in the CANs to promote larval development. By contrast, cell-

44 specific expression experiments suggest that kin-29 acts in both the

45 hypodermis and neurons, but not in the CANs. Based on our findings, we

46 propose that cAMP produced by ACY-2 in the CANs acts in neighboring neurons and hypodermal cells where it activates PKA and inhibits KIN-29 to

48 promote larval development. We discuss how this conserved pathway could

49 be partitioned between two cells. 


\section{INTRODUCTION}

51 The nematode Caenorhabditis elegans (C. elegans) requires only three

52 neurons for survival: the M4 motor neuron and the two Canal-Associated

53 Neurons (CANs). The M4 neuron is located in the pharynx, the C. elegans

54 feeding organ, and is required for peristaltic movements that move food along the pharynx (AVERY AND HORVITZ 1987; AVERY AND HORVITZ 1989). The CANs are two bilaterally symmetric neurons that are born in the head and migrate posteriorly to the middle of the worm during embryogenesis. After the CANs have completed their migration, each neuron extends two axons: one axon grows anteriorly towards the head, and the other grows posteriorly towards the tail (WHITE et al. 1976; Wu et al. 2011). If the CANs are killed by laser microsurgery or if the neurons fail to differentiate, the worms arrest their development early in larval development (FORRESTER AND GARRIGA 1997; FORRESTER et al. 1998). How the CANs regulate larval development is

64 unknown.

Phenotypic analysis of mutants with CAN defects also reveals their role in larval development. The CANs express two differentiation markers, the homeodomain transcription factors CEH-10 and CEH-23 (WANG et al. 1993; SVENDSEN AND MCGHEE 1995). Loss of ceh-10 also results in larval arrest, which is thought to result from the failure of the CANs to differentiate

71 (ForRESTER AND GARRIGA 1997; FORRESTER et al. 1998). The posteriorly

72 directed migrations of many cells and growth cones require the gene vab-8

73 (variable abnormal) (WIGHTMAN et al. 1996; WoLF et al. 1998). In vab-8 null 74 mutants, the CANs fail to migrate posteriorly, and their posterior axons fail to 
extend or extend a short distance. The posterior body of older vab-8 mutant larvae and adults becomes thin and develops abnormally. This withered tail (Wit) phenotype is thought to result from the lack of CAN function in the posterior of the mutant animals (WIGHTMAN et al. 1996), a hypothesis that is supported by a correlation in different mutants between the severity of the defect in the extension of the CAN posterior axon and the penetrance of the Wit phenotype (FORRESTER AND GARRIGA 1997).

In an attempt to reveal the function of the CANs, we mutagenized ceh-10 or vab-8 mutants and screened for mutations that can suppress the mutant larval arrest or Wit phenotypes without suppressing their CAN neuron defects. In our screens, we identified three alleles of kin-29, which encodes a serine/threonine kinase that is a member of the Salt-Inducible Kinase (SIK) family involved in the regulation of feeding and fasting states (Koo et al. 2005; DENTIN et al. 2007; WANG et al. 2008; CHOI et al. 2011).

The three mammalian SIKs are inhibited by a conserved G-protein Coupled Receptor (GPCR) pathway that activates adenylyl cyclase (ACY) and Protein Kinase A (PKA) (WANG et al. 1999; TAKEMORI et al. 2002; ОKAMOTO et al. 2004; VAN DER LINDEN et al. 2008). Here we report that mutations that cause an increase of cAMP levels or the activation of PKA rescue the ceh-10 larval arrest phenotype. We also provide evidence that ACY-2 is the adenylyl cyclase that generates the cAMP necessary for CAN-dependent larval development. ACY-2 is expressed in the CANs and in a few other neurons (KORSWAGEN et al. 1998). We found that when expressed in the CANs, acy-2 
partially rescued the mutant acy-2 larval arrest phenotype. Furthermore, CAN-

101 specific RNAi of acy-2 induced larval arrest. Together, these findings suggest

102 that ACY-2 produces CAMP in the CANs. To address where KIN-29 acts when

103 CAN function is defective, we performed cell-specific expression experiments

104 that suggest that KIN-29 functions in the hypodermis and neurons, but not in

105 the CANs. Our observations are consistent with a model where cAMP

106 produced by $\mathrm{ACY}-2$ in the CANs negatively regulates $\mathrm{KIN}-29$ in neurons and

107 hypodermal cells to promote larval development. We propose that cAMP

108 diffuses from the CANs through gap junctions to inhibit KIN-29 though PKA to

109 promote proper larval development.

111 Materials and Methods

\section{C. elegans genetics}

113 Worms were cultured as previously described (BRENNER 1974). All strains

114 were maintained at $20^{\circ} \mathrm{C}$, unless otherwise noted. The following mutant

115 alleles were used: LGI: gsa-1(ce94), lin-35(n745), mef-2(gv1) LGII: pde-

116 4(ce268) LGIII: acy-1(pk1279), ceh-10(gm58), rrf-3(pk1426) LGIV: eri-

117 1(mg366) LGV: acy-2(pk465), ergo-1(gg100), nre-1(hd20), rde-1(ne219),

118 vab-8(e1017) LGX: hda-4(oy59), kin-2(ce179), kin-29(gm112), kin-29(jehm1),

119 kin-29(jehm2), kin-29(gk288), lin-15B(n744), lin-15B(hd126)

120 Transgenes: gm/s18[Pceh-23::GFP;pRF4(rol-6su1006)] (ZINOVYEVA AND

121 FORRESTER 2005)

123 The double and triple mutants created in the genetic interaction studies were

124 sequenced to confirm that all mutations were present. 
ceh-10 and vab-8 suppressor screens

ceh-10(gm58)/ht2; gm/s18 or vab-8(e1017)gm/s18 worms were mutagenized

128 for 4 hours by incubation in $0.05 \mathrm{M}$ ethyl methane sulfonate (EMS). Worms

129 were washed in $\mathrm{M} 9$ buffer $\left(22 \mathrm{mM} \mathrm{KH}_{2} \mathrm{PO}_{4}, 42 \mathrm{mM} \mathrm{Na}_{2} \mathrm{HPO}_{4}, 85.5 \mathrm{mM} \mathrm{NaCl}\right.$

130 and $1 \mathrm{mM} \mathrm{MgSO}_{4}$ ) and placed on a large culture dish. 2 hours later L4

131 hermaphrodites were transferred to new plates in groups of five worms. Five

132 to six days later F1 progeny were picked individually to new plates and on day

$1339-13$, the F2 progeny were screened for ability to rescue ceh-10 larval arrest

134 or vab-8 withered tail phenotype. gm112 suppressed the vab-8 Wit phenotype

135 and jehm1 and jehm2 suppressed ceh-10 larval arrest. All suppressors were

136 outcrossed ten times to the wild-type N2 strain.

\section{Mutant identification}

139 For identification of kin-29(gm112), we used a combination of SNP mapping,

140 RNAi interference and sequencing. The Hawaiian isolate CB4856 was used

141 for SNP mapping (WICKS et al. 2001), which placed gm112 between SNPs in

142 the H01M10.1 and pccb-1 genes. Genes located between H01M10.1 and

$143 p c c b-1$ were tested for suppression of vab-8 Wit and ceh-10 larval arrest by

144 feeding worms bacteria expressing double-stranded RNA specific to a single

145 gene. RNAi clones were obtained from the Ahringer RNAi library (KAMATH et

146 al. 2003) or the C. elegans ORFeome library (RUAL et al. 2004) and were

147 verified by sequencing. The experiments were performed as previously

148 described (TIMmONs et al. 2001). 
150 RNAi against kin-29 rescued both vab-8 Wit and ceh-10 larval arrest

151 phenotypes. The mutant kin-29 genes were sequenced by amplifying

152 fragments covering the entire kin-29 gene by PCR.

\section{DNA plasmid constructs and transgenic lines}

154 Pges-1::kin-29cDNA was generated by PCR amplifying 3323 bp of the ges-1

155 promoter using wild type genomic DNA as template with the following primers:

156 5'-ctcgagctaagcttaatgaagtttatttc -3' (Xhol site underlined) and 5'-

157 ggatcctgaattcaaagataagatatgt-3'(BamHI site underlined). The PCR product

158 was cloned into $\mathrm{pCR}$ (2.1-TOPO® (Invitrogen), cut out with $\mathrm{Xhol}$ and BamHI

159 and ligated into pBluescriptKS-. 2468 bp kin-29cDNA was amplified from

160 Pkin-29::kin-29cDNA::GFP (a kind gift from Piali Sengupta) with the following

161 primers: 5'-ggatccatggctgcgccacggcggc-3'(BamHI site underlined) and 5'-

162 gcggccgctcactccgagctccagcttg-3'(Notl site underlined). The PCR product was

163 cloned into $\mathrm{PCR}$ (2.1-TOPO® (Invitrogen), cut out with BamHI and Notl and

164 ligated into Pges-1;pBluescriptKS-. 744 bp of unc-54 3'UTR was generated

165 by PCR amplification using wild type genomic DNA as template with the

166 following primers: 5'-gcggccgccatctcgcgcccgtgcctc-3'(Notl site underlined)

167 and 5'-gcggccgcaaacagttatgtttggtat-3' (Notl site underlined). The PCR

168 product was cloned into $\mathrm{pCR} \otimes 2.1-\mathrm{TOPO} \circledast$ (Invitrogen), cut out with Notl and

169 ligated into Pges-1::kin-29cDNA;pBluescriptKS- creating Pges-1::kin-

$17029 c D N A::$ unc-54 3'UTR. The plasmid was injected into ceh-10;kin-29 at 25

$171 \mathrm{ng} / \mu \mathrm{l}$ together with $2 \mathrm{ng} / \mu \mathrm{l}$ Pmyo-2::mCherry. 
173 Pges-1::GFP was generated by PCR amplifying 3323 bp of the ges-1

174 promoter using wild type genomic DNA as template with the following primers:

175 5'-ggatccctaagcttaatgaagtttatttc -3' (BamHI site underlined) and 5'-

176 ccatggctgaattcaaagataagatatgt-3'( $\mathrm{Ncol}$ site underlined). The PCR product

177 was cloned into $\mathrm{PCR}$ (2.1-TOPO® (Invitrogen), cut out with $\mathrm{BamHI}$ and $\mathrm{Ncol}$

178 and ligated into pPD95.77. The plasmid was injected into wild-type worms at

$17925 \mathrm{ng} / \mu \mathrm{l}$ together with $40 \mathrm{ng} / \mu \mathrm{l}$ pRF4 (rol-6 su1006).

180

181 Phlh-1:: kin-29cDNA was generated by PCR amplifying 3052 bp of the $h / h-1$

182 promoter using wild type genomic DNA as template with the following primers:

183 5'-ctgcagcagaattctgtgaaataagc-3' (Pstl site underlined) and 5'-

184 ggatccttctggaaaattattggaaaat-3'(BamHI site underlined). The PCR product

185 was cloned into $\mathrm{PCR}$ (2.1-TOPO® (Invitrogen), cut out with Pstl and BamHI

186 and ligated into pBluescriptKS-. The kin-29cDNA and unc-54 3'UTR was

187 amplified, cloned, cut and ligated as described for the Pges-1::kin-29cDNA

188 construct (see above). The plasmid was injected into ceh-10;kin-29 at 25

$189 \mathrm{ng} / \mu \mathrm{l}$ together with $2 \mathrm{ng} / \mu \mathrm{l}$ Pmyo-2::mCherry.

191 Phlh-1::GFP was generated by cutting out $P h l h-1$ from $\mathrm{pCR} 22.1-\mathrm{TOPO} \circledast$

192 (Invitrogen) (see above) with Pstl and BamHI and ligate the fragment into

193 pPD95.77. The plasmid was injected into wild-type worms at $25 \mathrm{ng} / \mu \mathrm{l}$ together

194 with $40 \mathrm{ng} / \mu \mathrm{l}$ pRF4 (rol-6 su1006). 
Pelt-3:: kin-29cDNA was generated by PCR amplifying 1964 bp of the elt-3

197 promoter using wild type genomic DNA as template with the following primers:

198 5' -ctgcagtgtgacacgttgtttcacggtc-3' (Pstl site underlined) and 5'-

199 ggatccgaagtttgaaataccaggtagc-3'(BamHI site underlined). The PCR product

200 was cloned into $\mathrm{pCR}$ 囚2.1-TOPO® (Invitrogen), cut out with Pstl and BamHI

201 and ligated into pBluescriptKS-. The kin-29cDNA and unc-54 3'UTR were

202 amplified, cloned, cut and ligated as described for the Pges-1::kin-29cDNA

203 construct (see above). The plasmid was injected into ceh-10;kin-29 at 25

$204 \mathrm{ng} / \mu \mathrm{l}$ together with $2 \mathrm{ng} / \mu \mathrm{l}$ Pmyo-2::mCherry.

Pelt-3::GFP was generated by cutting out Pelt-3 from pCR®2.1-TOPO $®$

207 (Invitrogen) (see above)

208 with Pstl and BamHI and ligate the fragment into pPD95.77. The plasmid was

209 injected into wild-type worms at $25 \mathrm{ng} / \mu \mathrm{l}$ together with $40 \mathrm{ng} / \mu \mathrm{l} p R F 4$ (rol-6

210 su1006).

212 Prab-3:: kin-29cDNA was generated by PCR amplifying 1329 bp of the rab-3

213 promoter using wild type genomic DNA as template with the following primers:

$214 \quad 5^{\prime}$-ctgcagcgaagctataatagttttc-3' (Pstl site underlined) and 5'-

215 ggatccggtcttcttcgtttccgcc-3'(BamHI site underlined). The PCR product was

216 cloned into $\mathrm{pCR} \otimes 2.1-\mathrm{TOPO} \otimes$ (Invitrogen), cut out with Pstl and BamHI and

217 ligated into pBluescriptKS-. The kin-29cDNA and unc-54 3'UTR was

218 amplified, cloned, cut and ligated as described for the Pges-1::kin-29cDNA 

together with $40 \mathrm{ng} / \mu \mathrm{l}$ pRF4 (rol-6 su1006). $\mathrm{ng} / \mu \mathrm{l}$ together with $2 \mathrm{ng} / \mu \mathrm{l}$ Pmyo-2::mCherry. (Invitrogen) (see above) su1006). ng/ $\mu$ l together with $2 \mathrm{ng} / \mu \mathrm{l}$ Pmyo-2::mCherry.

construct (see above). The plasmid was injected into ceh-10;kin-29 at 10

Prab-3::GFP was generated by cutting out Prab-3 from pCR®2.1-TOPO®

with Pst and BamHI and ligate the fragment into pPD95.77. The plasmid was injected into wild-type animals at $10 \mathrm{ng} / \mu \mathrm{l}$ together with $40 \mathrm{ng} / \mu \mathrm{l} p R F 4$ (rol-6

Pkin-29::kin-29cDNA was generated by PCR amplifying 1400 bp of the kin29 promoter using wild type genomic DNA as template with the following primers: 5'-ctgcagctattactgtaacacctcttac-3' (Pst/ site underlined) and 5'ggatcctgcagtgttggtgtggcggcgc-3'(BamHI site underlined). The PCR product was cloned into $\mathrm{pCR} \otimes 2.1-\mathrm{TOPO}($ (Invitrogen), cut out with Pst and BamHI and ligated into pBluescriptKS-. The kin-29cDNA and unc-54 3'UTR were amplified, cloned, cut and ligated as described for the Pges-1::kin-29cDNA construct (see above). The plasmid was injected into wild type worms at 25

Pkin-29::kin-29::GFP was generated by cutting out Pkin-29 from pCRß2.1TOPO® (Invitrogen) (see above) with Pstl and BamHI and ligate the fragment into pPD95.77. The plasmid was injected into wild-type animals at $25 \mathrm{ng} / \mu \mathrm{l}$ 
243 Pkin-29::kin-29SER517ALA was generated by modifying Pkin-29::kin-

244 29cDNA using PCR-based mutagenesis (Quickchange II XL site-directed

245 mutagenesis kit, Stratagene). The following primers were used: 5'-

246 ccaaagagtgaacgccgagctgccgccggtgaaactcttctgcc-3' and its reverse

247 complement. The plasmid was injected into wild type worms at $25 \mathrm{ng} / \mu \mathrm{l}$

248 together with $2 \mathrm{ng} / \mu \mathrm{l}$ Pmyo-2::mCherry.

Pceh-23_L::acy-2 fragment (sense/anti-sense) Pceh-23_L::acy-2

251 fragment(sense) was generated with a Gibson assembly cloning kit (NEB) by

252 assembly of the following two DNA fragments: (1) Pceh-23_L that was

253 amplified from Pceh-23_L::unc-53cDNA with the primers: 5'-

254 ggtactccagccgactccatatgattgcggccgcattttcaaattttaaata-3'and 5'-

255 ctactctccctgtttccagcttatggetgcagttttctaccggtaccctca-3'and (2) 1252 bp acy-2

256 genomic fragment that was amplified from N2 genomic DNA with the primers:

$2575^{\prime}$ - tgagggtaccggtagaaaaactgcagccataagctggaaacagggagagtag-3'and 5'-

258 tatttaaaattgaaaatgcggccgcaatcatatggagtcggctggagtacc-3'.

260 Pacy-2::acy-2 genomic was generated with a Gibson assembly cloning kit

261 (NEB) by assembly of the following two DNA fragments: (1) 1200 bp Pacy-2

262 that was amplified from wild-type genomic DNA template with the primers: $5^{\prime}-$

263 gctgtctactgccaaatacgtc-3'and 5' - tgcgcgcctggaattcagg-3'and (2) acy-2

264 genomic backbone that was amplified from Pceh-23_L::acy-2(genomic) with

265 the primers: $5^{\prime}$ - cctgaattccaggcgcgcaatgtcgacagtgatggaaatgtcgacg-3'and $5^{\prime}-$

266 gacgtatttggcagtagacagccccagcttttgttccetttagtg-3'. 
Pacy-2::acy-2 genomic was injected into wild-type worms at $20 \mathrm{ng} / \mu \mathrm{l}$ with 3

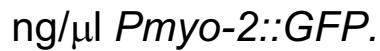

269

Pceh-23_L::acy-2 fragment(anti-sense) was generated with a Gibson

(1) Pceh-23_L that was amplified from Pceh-23_L::unc-53cDNA with the

primers: 5'- ctactctccetgtttccagcttatgggcggccgcatttcaaattttaaata-3'and 5'-

ggtactccagccgactccatatgattctgcagttttctaccggtaccctca-3'and (2) 1252 bp acy-2 genomic fragment that was amplified from N2 genomic DNA with the primers:

$5^{\prime}$ - tgagggtaccggtagaaaaactgcagaatcatatggagtcggctggagtacc-3'and 5'-

277 tattlaaaattgaaaatgcggccgcccataagctggaaacagggagagtag-3'.

278 Pceh-23::acy-2 fragment(sense) and Pceh-23::acy-2 fragment(anti-sense)

279 were injected together into wild type worms at $20 \mathrm{ng} / \mu \mathrm{l}$ each with $3 \mathrm{ng} / \mu \mathrm{l}$

280 Pmyo-2::GFP.

Pceh-23_L::acy-2(genomic) was generated with a Gibson assembly cloning

283 kit (NEB) by assembly of the following two DNA fragments: (1) Pceh-23_L

284 that was amplified from Pceh-23_L::GFP with the primers: 5'-

285 gacactccaaaattttccaaacttaacttataaatcaaaagaatagaccgaga-3'and 5'-

286 cgtcgacatttccatcactgtcgacatctgcagttttctaccggtaccctca-3'and (2) acy-2

287 genomic DNA that was amplified from N2 genomic DNA with the primers: 5'-

288 tgagggtaccggtagaaaaactgcagatgtcgacagtgatggaaatgtcgacg-3'and 5'-

289 tctcggtctattctttgatttataagttaagtttggaaaatttggagtgtc-3'. Pceh-23_L::acy- 
2(genomic) was injected into wild type worms at $20 \mathrm{ng} / \mu \mathrm{l}$ together with $3 \mathrm{ng} / \mu \mathrm{l}$

291 Pmyo-2::GFP.

293 Germline transformation was performed by direct injection of various plasmid

294 DNAs into the gonads of adult wild-type animals as described (MELLO et al.

295 1991).

\section{Survival assay}

298 Eggs were transferred to fresh NGM plates and allowed to hatch. The newly

299 hatched L1 larvae were transferred to new plates and the stage of the worms

300 were studied after 24, 48 and 72 hrs. At least 3 biological replicates have

301 been performed for each strain. Error bars show the 95\% confidence interval

302 determined by Z-tests. The p-values are calculated using Fisher's exact test.

\section{cAMP feeding}

8-Br-cAMP (Tocris) was mixed with fresh growing E.coli (OP50) bacteria

306 (grown over night in Luria Broth media with shaking at $37^{\circ} \mathrm{C}$ ). $75 \mu$ of

307 bacteria-cAMP mix was seeded onto small NGM plates and the plates were

308 allowed to dry for $1 \mathrm{~h}$. Worms were transferred to the plates and immediately

309 another batch of $75 \mu \mathrm{l}$ bacteria-cAMP mix was added on top of the worms.

310 For survival studies, eggs from mothers previously grown on cAMP plates

311 were transferred to new cAMP plates and were allowed to hatch and develop

312 for $72-96$ hrs and then the stage of the worms were determined. 


\section{Fluorescence microscopy}

315 Worms were anesthetized in $10 \mathrm{mM}$ levamisole. A Zeiss Axioskop 2

316 microscope was used to examine worms. Images were collected using an

317 ORCA-ER CCD camera (Hamamatsu) and Openlab imaging software

318 (Improvision).

Results

Mutations in kin-29 rescued phenotypes caused by defective CANs.

322 The two bilaterally symmetric $C$. elegans CANs are generated in the head and

323 migrate toward the tail to occupy positions near the center of the embryo

324 (SULSTON 1983). Each CAN extends an anterior axon to the head and a

325 posterior axon to the tail (WHITE et al. 1986; Wu et al. 2011) (Figure 1A).

326 Normal morphogenesis and larval development require CAN neuron function

327 (FORRESTER AND GARRIGA 1997; FORRESTER et al. 1998). In mutants lacking

328 vab-8 function, for example, the CAN cell bodies usually fail to migrate and

329 either lack or have short posterior axons (HEDGECOCK et al. 1987; MANSER

330 AND WOOD 1990; WightMAN et al. 1996; AdLER et al. 2006) (Figure 1C). The

331 lack of CAN function in the posterior of vab-8 mutants is thought to result in

332 thinning of the posterior body, the Withered tail (Wit) phenotype (Figure 1D).

333 In ceh-10(gm58) mutants, the CANs cannot be detected using Nomarski

334 optics or a CAN differentiation marker, and the worms arrest as early larvae

335 (Fig 1G-H) (FORRESTER AND GARRIGA 1997; FORRESTER et al. 1998). Because

336 laser killing of the CANs also results in a larval arrest (FORRESTER AND

337 GARRIGA 1997), the developmental arrest phenotype of ceh-10 mutants is

338 thought to result from loss of CAN function. It is unclear, however, whether the 
339 CANs are absent in ceh-10(gm58) mutants or whether they are present but

340 fail to differentiate.

342 To investigate how the CANs regulate larval development, we carried out two

343 suppressor screens. In the first screen, we mutagenized vab-8(e1017)

344 mutants and screened for suppressor mutations that rescued the Wit

345 phenotype without rescuing the CAN migration or axon extension defects and

346 identified kin-29(gm112). Because this mutation also suppressed the larval

347 arrest phenotype of ceh-10 mutants (see below), we mutagenized ceh-

348 10(gm58) mutants and screened for mutations that suppressed the larval

349 arrest phenotype but did not restore the CANs based on our inability to detect

350 the cells using Nomarski optics or a Pceh-23::gfp reporter transgene. In this

351 screen, we isolated four suppressed strains. Two of these strains contained

352 the kin-29(jehm1) or kin-29(jehm2) mutations (Figure 1, E-F, I-J).

354 kin-29 encodes a serine/threonine kinase that is homologous to the Salt-

355 Inducible Kinases (SIKs) that are related to the AMPK/SNF1 family of kinases

356 (LANJUIN AND SENGUPTA 2002). Sequencing of the kin-29 gene from the

357 different mutants revealed that the jehm1 allele is a missense mutation that

358 changes a conserved glutamate in the kinase domain to lysine (E112K), that

359 the jehm2 allele is a nonsense mutation that changes a conserved tryptophan

360 in the kinase domain to an amber stop codon (W172STOP), and that the

361 gm112 allele is a nonsense mutation that changes a glutamine to an amber

362 stop codon (Q447STOP) (Figure 1K). We also analyzed the kin-29(gk288)

363 allele isolated by the International C. elegans Gene Knockout Consortium. 
364 The 575 bp deletion removes most of the kinase domain and results in a

365 downstream frameshift. All of the kin-29 mutant alleles rescued the vab-8 Wit

366 phenotype (data not shown), and by scoring the ability of animals to develop

367 past the third larval (L3) stage, all of the kin-29 mutant alleles also suppressed

368 the ceh-10 mutant larval arrest phenotype (Figure $1 \mathrm{~L}$ ). These findings indicate

369 that the morphological and larval arrest phenotypes caused by CAN

370 dysfunction or loss require kin-29 function. In all of the studies described

371 below, we used the kin-29(gm112) allele.

\section{kin-29 functions in neurons and hypodermal cells to mediate CAN}

\section{4 function.}

375 To determine where the kin-29 mutations act to suppress the ceh-10 larval

376 arrest phenotype, we expressed a kin-29 cDNA from cell-specific promoters in

377 ceh-10; kin-29 double mutants and asked whether kin-29 expression in

378 specific cell types produced the larval arrest phenotype of the ceh-10 single

379 mutant. We tested expression in intestine, body-wall muscle, hypodermal cells

380 and neurons, cell types known to express kin-29 (MADUZIA et al. 2005). For

381 intestinal expression we used the ges-1 promoter (AAMODT et al. 1991), for

382 body-wall muscle expression we used the hlh-1 promoter (QADOTA et al.

383 2007), and for hypodermal expression we used the elt-3 promoter (GILLEARD

384 et al. 1999). For neuronal expression we used the rab-3 promoter, which is

385 expressed in all neurons except the CANs (STEFANAKIS et al. 2015). To

386 confirm that the promoters used to drive kin-29 in these cells were indeed

387 specific, we also fused the promoters to the GFP gene, studied the

388 expression of the transgenic animals at different developmental stages and 
389 found that the promoters drove expression in the predicted cells (data not

390 shown). Only when neurons or hypodermal cells expressed the kin-29 cDNA

391 was the ceh-10 larval arrest phenotype restored, suggesting that deregulated

392 kin-29 activity in either neurons (other than the CANs) or hypodermal cells is

393 sufficient to arrest larval development (Figure 1M).

Because all known CAN promoters require ceh-10 function, we were unable to confirm that kin-29 does not act in the CANs to suppress ceh-10 lethality.

However, we were able to express a kin-29 cDNA in the CANS of vab-8; kin29 double mutants since the CANs are present in these animals. To ensure specific expression in the CANs, we used a part of the ceh-23 promoter that 400 drives expression only in the CANs (Pceh-23_L) (WENICK AND HOBERT 2004).

401 CAN-specific expression of kin-29 did not restore the Wit phenotype $(N=50)$, 402 consistent with the hypothesis that $\mathrm{KIN}-29$ acts neurons and the hypodermis 403 to mediate the effects of CAN function.

Loss of the MEF-2 MADS domain transcription factor also rescues ceh10 mutant larval arrest

407 In C. elegans and cultured cells, SIKs phosphorylate and inhibit class II

408 histone deacetylases, which act either upstream of or in a complex with the

409 transcription factor MEF2 to regulate gene transcription (MISKA et al. 1999;

410 LANJUIN AND SENGUPTA 2002; CHAN et al. 2003; VAN DER LINDEN et al. 2008;

411 COHEN et al. 2009). Loss of the C. elegans homologs of MEF2 (mef-2) and

412 the class Ila HDACs (hda-4) suppress several kin-29 mutant phenotypes:

413 small body size, long lifespan, slow growth, hyper-foraging and 
414 chemoreceptor gene regulation (VAN DER LINDEN et al. 2007). If the sole

415 activity of KIN-29 in suppressing the larval arrest phenotype of ceh-10

416 mutants is to inhibit the function of a HDA-4/MEF-2 repressive complex, then

417 hda-4 and mef-2 mutants should exhibit a larval arrest phenotype similar to

418 ceh-10 mutants, but both hda-4 and mef-2 mutants are viable and fertile.

420 To determine if HDA-4 and MEF-2 function differently in the regulation of

421 morphogenesis and larval development, we asked whether mutations in these

422 genes interacted with a ceh-10 mutation. Although an hda-4 mutation had no

423 effect on the ceh-10 larval arrest phenotype, both the mef-2(gv1) mutation

424 and mef-2(RNAi) suppressed larval arrest (Figures 1L and 2). The ceh-10;

425 mef-2; kin-29 triple mutant has survival rates similar to the ceh-10; kin-29 and

426 ceh-10; mef-2 double mutants. These findings indicate that the functional

427 relationship between kin-29 and mef-2 differs in chemoreceptor regulation and

428 CAN-dependent larval development.

Mutations that upregulate the cAMP-dependent PKA pathway

432 cAMP-dependent protein kinase A (PKA) inhibits KIN-29 and its SIK

433 homologs at both the transcriptional and post-translational levels (TAKEMORI et 434 al. 2002; OKAMOTO et al. 2004; BERDEAUX et al. 2007; VAN DER LINDEN et al. 435 2008; WANG et al. 2008). In C. elegans, PKA consists of two subunits, the 436 catalytic subunit $\mathrm{KIN}-1$ and the regulatory subunit $\mathrm{KIN}-2$. PKA is activated by 437 cAMP that is produced by adenylyl cyclases. One of these, ACY-1, can be 438 activated by the heterotrimeric G protein GSA-1 (BERGER et al. 1998). Loss of 
439 acy-1, gsa-1, kin-1, and kin-2 result in embryonic or larval lethality. If the

440 proteins encoded by these genes inhibit KIN-29 function, then like loss-of-

441 function mutations in kin-29, gain-of-function mutations in these genes might

442 also suppress the larval arrest phenotype of ceh-10 mutants. kin-2(ce179)

443 mutants express a PKA holoenzyme that is hypersensitive to low levels of 444 cAMP, and gsa-1(ce94) mutants express a $\mathrm{G} \alpha$ protein that constitutively

445 activates PKA (KoRsWAgen et al. 1997; SCHADE et al. 2005; CHARLIE et al.

446 2006). Similar to the kin-29 loss-of-function mutations, the gain-of-function

447 kin-2(ce179) and gsa-1(ce94) mutations suppressed the ceh-10 larval arrest 448 phenotype without suppressing the CAN defects of ceh-10 mutants (Figure 2 449 and data not shown).

451 We also asked whether elevating the levels of cAMP could suppress the ceh-

45210 larval arrest phenotype. The gene pde-4 encodes a cAMP

453 phosphodiesterase that is homologous to human cAMP phosphodiesterase

454 4D (CHARLIE et al. 2006). cAMP phosphodiesterases convert cAMP to 5'-AMP

455 and thus lower cAMP levels (SUNAHARA et al. 1996). The pde-4(ce268)

456 mutation disrupts the PDE-4 catalytic domain and reduces PDE-4 function,

457 which is predicted to increase cAMP levels (CHARLIE et al. 2006). This

458 mutation suppressed ceh-10 mutant lethality (Figure 2).

\section{Hyperactive KIN-29 results in larval arrest}

461 We asked if we could phenocopy the larval arrest phenotype of ceh-10

462 mutants by introducing a hyperactive version of KIN-29 into wild-type

463 hermaphrodites. We created a construct with a mutation in the conserved 
464 PKA phosphorylation site (Ser 517-Ala) (TAKEMORI et al. 2002; VAN DER LINDEN

465 et al. 2008) and expressed it using the kin-29 promoter, Pkin-29::kin-

466 29cDNA(Ser517-Ala). As controls, we made two constructs lacking the

467 mutation, Pkin-29::kin-29cDNA and Pkin-29::GFP. The control constructs

468 were injected into wild-type worms, creating several stable transgenic lines

469 lacking obvious phenotypes. The construct with the kin-29 promoter driving

470 GFP showed the same expression pattern as described previously (LANJUIN

471 AND SENGUPTA 2002). We injected the mutated construct into wild-type

472 hermaphrodites, and $72 \%(\mathrm{~N}=58)$ of the transgenic worms arrested as early

473 larvae. The surviving transgenic worms failed to produce lines. This finding is

474 consistent with the hypothesis that $\mathrm{KIN}-29$ is a PKA target.

ACY-2 functions in the CANs to produce essential levels of CAMP

477 Our results suggest that the CANs signal to the hypodermis and other

478 neurons, activating PKA in these tissues. PKA represses KIN-29, which

479 allows larval development to proceed. Because the pde-4 mutation rescued

480 the ceh-10 larval arrest phenotype to a similar degree as the kin-29 mutations,

481 we asked if exogenous cAMP could also rescue ceh-10 loss. To explore this

482 possibility, we fed ceh-10 mutants a synthetic version of cAMP, 8-Br-cAMP,

483 which is a cell-permeable cAMP analog that is resistant to hydrolysis by

484 phosphodiesterases (SANDBERG et al. 1991). We tested different

485 concentrations and found that $5 \mathrm{mM}$ 8-Br-cAMP gave the best rescue with

$48675 \%$ of the ceh-10 mutants developing past the L3 stage (Figure 3 ). The ceh-

48710 mutants could be maintained for generations on 8-Br-cAMP but arrested

488 development if they were moved back to media lacking it (data not shown). 
cAMP is synthesized from ATP by adenylyl cyclases (ACYs). C. elegans has

491 which is broadly expressed in neurons and body wall muscles (MOORMAN AND

492 PLASTERK 2002), the other three ACYs have relatively restricted expression

493 patterns. For example, ACY-2 is only expressed in a few neurons in head

494 ganglia and in the CANs (KoRSWAGEN et al. 1998) (Table 1). Loss-of-function

495 mutations in acy-1 or acy-2 result in larval arrest (KORSWAGEN et al. 1998;

496 MOORMAN AND PLASTERK 2002), which prompted us to examine if acy-1 and

497 acy-2 mutants arrest development in a similar way to ceh-10 mutants. The

498 acy-1(pk1279), acy-2(pk465) and ceh-10(gm58) mutants were maintained as

499 balanced strains. To score the arrested larvae, we picked newly hatched

500 worms that lacked the balancer chromosome and scored their phenotypes

501 after $72 \mathrm{hrs}$. We noted that the arrested larvae displayed three different

502 phenotypes: normal (Figure 4A), morphological defective (Figure 4B) or clear

503 (Figure 4C). Most of the acy-1 arrested worms appeared normal, while acy-2

504 and ceh-10 mutants displayed the morphological defective and clear

505 phenotypes at similar frequencies (Figure 4D). We then asked if acy-1 and

506 acy-2 mutants could be rescued by the same mutations and treatments as

507 ceh-10. The pde-4 mutation was previously shown to partly suppress the acy-

5081 mutant (CHARLIE et al. 2006), and we found that it also rescued the acy-2

509 mutant (Figure 4E). Feeding acy-2 mutants with 8-Br-cAMP also rescued

510 larval arrest (Figure 4E). These findings are not unexpected for an adenylyl

511 cyclase mutant. The kin-29 or mef-2 mutations, however, suppressed the

512 acy-2 but not the acy-1 mutant phenotypes, consistent with the hypothesis 
513 that CAMP produced by ACY-2 negatively regulates $\mathrm{KIN}-29$ to promote larval

514 development (Figure 4E, and data not shown).

515 Mutations in kin-29 and mef-2 rescued the acy-2 and ceh-10 mutant defects

516 slightly better than kin-29 and mef-2 RNAi (Figures 2, 5A and data not

517 shown). It is noteworthy that many of the RNAi-treated acy-2 and ceh-10

518 mutant worms became visibly sick hours after being transferred to plates with

519 bacteria that did not express kin-29 or mef-2 dsRNA (data not shown),

520 suggesting that the activities of KIN-29 and MEF-2 need to be continuously

521 provided for acy-2 and ceh-10 worms to survive. These observations imply

522 that CANs need to constantly signal, presumably by producing cAMP that acts

523 in the nervous system and hypodermis.

524 The expression pattern of ACY-2 suggests that it could act in the CANs to

525 promote larval development. To test this hypothesis, we expressed ACY-2

526 specifically in the CANs of acy-2 mutants. Our attempt to isolate an acy-2

527 cDNA was unsuccessful, possibly because acy-2 is only expressed in a few

528 cells (KORSWAGEN et al. 1998). Instead, we expressed acy-2 genomic DNA

529 fused to GFP under the control of the CAN-specific promoter Pceh-23_L

530 (WENICK AND HOBERT 2004). We generated two independent, non-integrated

531 transgenic lines (Pceh-23_L::acy-2(genomic)::GFP), and only the CANs and a

532 single tail neuron expressed these transgenes (not shown). We compared

533 transgenic and non-transgenic worms originating from the same transgenic

534 mother. Both transgenic lines rescued the larval arrest phenotype, with more

535 than $40 \%$ of the transgenic worms developing past L3 stage (Figure 5b). We

536 also generated transgenic lines that express acy-2 from its endogenous 
537 promoter (Pacy-2::acy-2(genomic). We observed a more robust rescue

538 compared to CAN-specific expression of ACY-2 with more than $90 \%$ of the

539 transgenic worms developing past the L3 stage. This finding suggests either

540 that the endogenous promoter drives higher levels of acy-2 in the CANs or

541 that neurons other than the CANs are also important for acy-2 mutant larvae

542 to develop.

543

544 As an alternative test of this hypothesis, we performed CAN-specific acy-2

545 RNAi to ask if we could phenocopy the acy-2 mutant phenotype. We

546 generated transgenes that expressed both acy-2 sense and acy-2 antisense

547 RNA driven from the CAN promoter to generate acy-2 dsRNA in the CANs.

548 These transgenes were expressed in an ergo-1 mutant to sensitize the

549 background to RNAi effects (PAVELEC et al. 2009). To obtain viable transgenic

550 lines, we grew the worms on plates with bacteria that produced dsRNA that

551 targeted kin-29, transferred transgenic worms to plates with control bacteria

552 that did not express kin-29 dsRNA and scored survival in the next generation.

553 As a control, we subjected acy-2(pk465) mutants to the same protocol. When

554 the Pceh-23_L::acy-2(RNAi) transgenic worms and the acy-2 mutants were

555 transferred to plates with control bacteria, both strains arrested development

556 at similar frequencies (Figure 5A). These findings further support the

557 hypothesis that ACY-2 can act in the CANs to promote larval development. 
561 The function of the CANs is mysterious. It has been proposed that the CANs

562 regulate the function of the excretory canal cell, which is involved in

563 osmoregulation (HEDGECOCK et al. 1987; FoRRESTER AND GARRIGA 1997). This

564 hypothesis is based on the accumulation of fluid in the pseudocoelom, the

565 Clear (Clr) phenotype, in animals missing their CANs. In screens for

566 mutations that bypass the requirement for the CANs in larval development, we

567 identified the gene kin-29, which encodes a SIK homolog, and showed that

568 the CANs regulate a conserved cAMP pathway that inhibits kin-29.

570 The KIN-29/SIK pathway mediates diverse functions that range from

571 transcriptional regulation of $C$. elegans chemoreceptors to lipid metabolism in 572 adipocytes (VAN DER LINDEN et al. 2007; HENRIKSSON et al. 2012). In C.

573 elegans, kin-29 functions in sensory neurons to regulate body size, entry into

574 the dauer stage, and foraging behavior (LANJUIN AND SENGUPTA 2002;

575 MADUZIA et al. 2005). Although the CANs have no obvious role in any of these

576 processes, the essential nature of the cell makes testing its role in other

577 processes difficult. In this context, it is noteworthy that the analogous cell in

578 the nematode Pristionchus pacificus expresses the gene dauerless, which

579 antagonizes dauer development. Although killing the CAN-like cell in this

580 species does not cause larval arrest, it does cause entry into dauer,

581 presumably due to the lack of dauerless expression (MAYER et al. 2015).

582

583 Suppression of the ceh-10 larval arrest phenotype by mutations in genes that

584 act in the kin-29 pathway suggests that the adenylyl cyclase ACY-2 acting

585 through PKA inhibits KIN-29 activity, allowing larval development to progress. 
586 It is unclear whether the CANs and this pathway regulate larval development

587 directly or a physiological state that allows development to proceed.

588

589 SIKs inhibit the function of class lla histone deacetylases, which can interact

590 with the MEF2 transcription factor to repress the transcription of target genes

591 (DI GIORGIO AND BRANCOLINI 2016). The sole C. elegans member of the class

592 Ila HDAC family is HDA-4. Mutations in either hda-4 or mef-2 suppress the

593 effects of kin-29 mutations on chemoreceptor gene transcription, consistent

594 with the inhibition of HDA-4/MEF-2 repressor activity by KIN-29 (VAN DER

595 LINDEN et al. 2007). If KIN-29 inhibits HDA-4/MEF-2 repressor functions in

596 larval development as it does in chemoreceptor regulation, hda-4 and mef-2

597 mutations should cause larval arrest, which they do not. The mef-2 mutation,

598 however, suppressed the larval arrest phenotype of the ceh-10 mutant. One

599 model to explain these observations is that KIN-29 activates MEF-2, either

600 directly or indirectly. Stimulation of cortical neurons by BDNF results in the

601 activation of MEF2 transcriptional targets. In these cells, SIK1 phorphorylates

602 the class Ila histone deacetylase HDAC5, resulting in HDAC5 export from the

603 nucleus and allowing MEF2 to function as a transcriptionally activator

604 (FINSTERWALD et al. 2013). KIN-29 could also indirectly activate MEF-2

605 function in larval development, but our genetic results indicate that a protein

606 other than HDA-4 would link KIN-29 to MEF-2 function.

607

608

cAMP transport to target tissues

609 cAMP has traditionally been described as an intracellular "secondary

610 messenger" that is released in response to signals from "first messengers." If 
611 the hypothesis suggested by our results is correct, how then can cAMP

612 produced in the CANs regulate $\mathrm{KIN}-29$ in other cell types? One interesting

613 possibility is cAMP could diffuse between the CAN and other cells via gap

614 junctions, intercellular channels that allow passive transport of ions and small

615 molecules. Vertebrate gap junctions are hemichannels that consist of

616 connexin (Cx) proteins (ELFGANG et al. 1995). Several studies have shown

617 that cAMP diffuses between cells via connexins; for example, it is well

618 established that cAMP passes through the Cx26, Cx32, Cx36, Cx43, Cx45

619 and Cx47 gap junction channels in Hela cells (BEDNER et al. 2003; BEDNER et

620 al. 2006; HERNANDEZ et al. 2007; CHANDRASEKHAR et al. 2013).

621

622 In support of this hypothesis, larval development requires gap junction

623 function. C. elegans gap junctions are assembled from innexin (INX) proteins

624 (PHELAN et al. 1998). The CANs express the innexin genes inx-3, inx-12 and

625 inx-13 (ALTUN et al. 2009), and RNAi of inx-3 and mutations in inx-12 and inx-

62613 result in larval arrest (JOHNSEN et al. 2000; STARICH et al. 2001; SIMMER et

627 al. 2003; HALL 2016). CAN-specific RNAi of inx-13 also produced larval arrest

628 (not shown), which suggests that the gap junctions between the CANs and

629 other cells promote larval development. However, loss of neither kin-29 nor

630 mef-2 suppressed the larval arrest phenotype of inx-12 and inx-13 mutants

631 (not shown). The lack of suppression may reflect the expression of inx-12 and

632 inx-13 in other cell types such as pharynx and muscle, where they could

633 function to promote larval development. Further experiments will be required

634 to test this interesting hypothesis. 
bioRxiv preprint doi: https://doi.org/10.1101/733618; this version posted August 15, 2019. The copyright holder for this preprint (which was

not certified by peer review) is the author/funder, who has granted bioRxiv a license to display the preprint in perpetuity. It is made available under aCC-BY-NC-ND 4.0 International license.

636

637

638

639

640

641

642

643

644

645

646

647

648

649

650

651

652

653

654

655

656

657

658

659

660

661

662

663

664

665

666

667

\section{Acknowledgments}

The authors thank Dawna Sweeney and Ranjan Devkota for assistance in the lab and valuable discussions. We thank Piali Sengupta for the plasmid containing Pkin-29::kin-29cDNA::GFP. Some of the nematode strains used in this study were provided by the Caenorhabditis Genetics Center, which is funded by the NIH National Center for Research Resources (NCRR). The kin29(gk288) strain was provided by the C. elegans Gene Knockout Facility at the Oklahoma Medical Research Foundation (funded by the National Institutes of Health) and the C. elegans Reverse Genetics Core Facility at the University of British Columbia (funded by the Canadian Institute for Health Research, Genome Canada, Genome BC, the Michael Smith Foundation, and the National Institutes of Health). This work was supported by National Institutes of Health grant NS32057 to G.G.

\section{Literature Cited}

Aamodt, E. J., M. A. Chung and J. D. McGhee, 1991 Spatial control of gut-specific gene expression during Caenorhabditis elegans development. Science 252: 579-582.

Adler, C. E., R. D. Fetter and C. I. Bargmann, 2006 UNC-6/Netrin induces neuronal asymmetry and defines the site of axon formation. Nat Neurosci 9: 511-518.

Altun, Z. F., B. Chen, Z. W. Wang and D. H. Hall, 2009 High resolution map of Caenorhabditis elegans gap junction proteins. Dev Dyn 238: 1936-1950.

Ashrafi, K., F. Y. Chang, J. L. Watts, A. G. Fraser, R. S. Kamath et al., 2003 Genome-wide RNAi analysis of Caenorhabditis elegans fat regulatory genes. Nature 421: 268-272.

Avery, L., and H. R. Horvitz, 1987 A cell that dies during wild-type C. elegans development can function as a neuron in a ced-3 mutant. Cell 51: 1071-1078.

Avery, L., and H. R. Horvitz, 1989 Pharyngeal pumping continues after laser killing of the pharyngeal nervous system of C. elegans. Neuron 3: 473-485.

Bedner, P., H. Niessen, B. Odermatt, M. Kretz, K. Willecke et al., 2006 Selective permeability of different connexin channels to the second messenger cyclic AMP. J Biol Chem 281: 6673-6681. 
Bedner, P., H. Niessen, B. Odermatt, K. Willecke and H. Harz, 2003 A method to determine the relative cAMP permeability of connexin channels. Exp Cell Res 291: 25-35.

Berdeaux, R., N. Goebel, L. Banaszynski, H. Takemori, T. Wandless et al., 2007 SIK1 is a class II HDAC kinase that promotes survival of skeletal myocytes. Nat Med 13: 597-603.

Berger, A. J., A. C. Hart and J. M. Kaplan, 1998 G alphas-induced neurodegeneration in Caenorhabditis elegans. J Neurosci 18: 2871-2880.

Brenner, S., 1974 The genetics of Caenorhabditis elegans. Genetics 77: 71-94.

Chan, J. K., L. Sun, X. J. Yang, G. Zhu and Z. Wu, 2003 Functional characterization of an amino-terminal region of HDAC4 that possesses MEF2 binding and transcriptional repressive activity. J Biol Chem 278: 23515-23521.

Chandrasekhar, A., E. A. Kalmykov, S. R. Polusani, S. A. Mathis, S. N. Zucker et al., 2013 Intercellular redistribution of cAMP underlies selective suppression of cancer cell growth by connexin26. PLoS One 8: e82335.

Charlie, N. K., A. M. Thomure, M. A. Schade and K. G. Miller, 2006 The Dunce cAMP phosphodiesterase PDE-4 negatively regulates G alpha(s)-dependent and $\mathrm{G}$ alpha(s)-independent cAMP pools in the Caenorhabditis elegans synaptic signaling network. Genetics 173: 111-130.

Choi, S., W. Kim and J. Chung, 2011 Drosophila salt-inducible kinase (SIK) regulates starvation resistance through cAMP-response element-binding protein (CREB)-regulated transcription coactivator (CRTC). J Biol Chem 286: 26582664.

Cohen, T. J., T. Barrientos, Z. C. Hartman, S. M. Garvey, G. A. Cox et al., 2009 The deacetylase HDAC4 controls myocyte enhancing factor-2-dependent structural gene expression in response to neural activity. FASEB J 23: 99-106.

Dentin, R., Y. Liu, S. H. Koo, S. Hedrick, T. Vargas et al., 2007 Insulin modulates gluconeogenesis by inhibition of the coactivator TORC2. Nature 449: 366369.

Di Giorgio, E., and C. Brancolini, 2016 Regulation of class IIa HDAC activities: it is not only matter of subcellular localization. Epigenomics 8: 251-269.

Elfgang, C., R. Eckert, H. Lichtenberg-Frate, A. Butterweck, O. Traub et al., 1995 Specific permeability and selective formation of gap junction channels in connexin-transfected HeLa cells. J Cell Biol 129: 805-817.

Finsterwald, C., A. Carrard and J. L. Martin, 2013 Role of salt-inducible kinase 1 in the activation of MEF2-dependent transcription by BDNF. PLoS One 8: e54545.

Forrester, W. C., and G. Garriga, 1997 Genes necessary for C. elegans cell and growth cone migrations. Development 124: 1831-1843.

Forrester, W. C., E. Perens, J. A. Zallen and G. Garriga, 1998 Identification of Caenorhabditis elegans genes required for neuronal differentiation and migration. Genetics 148: 151-165.

Gilleard, J. S., Y. Shafi, J. D. Barry and J. D. McGhee, 1999 ELT-3: A Caenorhabditis elegans GATA factor expressed in the embryonic epidermis during morphogenesis. Dev Biol 208: 265-280.

Govindan, J. A., S. Nadarajan, S. Kim, T. A. Starich and D. Greenstein, 2009 Somatic cAMP signaling regulates MSP-dependent oocyte growth and meiotic maturation in C. elegans. Development 136: 2211-2221. 
Hall, D. H., 2016 Gap junctions in C. elegans: Their roles in behavior and development. Dev Neurobiol.

Hedgecock, E. M., J. G. Culotti, D. H. Hall and B. D. Stern, 1987 Genetics of cell and axon migrations in Caenorhabditis elegans. Development 100: 365-382.

Henriksson, E., H. A. Jones, K. Patel, M. Peggie, N. Morrice et al., 2012 The AMPKrelated kinase SIK2 is regulated by cAMP via phosphorylation at Ser358 in adipocytes. Biochem J 444: 503-514.

Hernandez, V. H., M. Bortolozzi, V. Pertegato, M. Beltramello, M. Giarin et al., 2007 Unitary permeability of gap junction channels to second messengers measured by FRET microscopy. Nat Methods 4: 353-358.

Johnsen, R. C., S. J. Jones and A. M. Rose, 2000 Mutational accessibility of essential genes on chromosome I(left) in Caenorhabditis elegans. Mol Gen Genet 263: 239-252.

Kamath, R. S., A. G. Fraser, Y. Dong, G. Poulin, R. Durbin et al., 2003 Systematic functional analysis of the Caenorhabditis elegans genome using RNAi. Nature 421: 231-237.

Koo, S. H., L. Flechner, L. Qi, X. Zhang, R. A. Screaton et al., 2005 The CREB coactivator TORC2 is a key regulator of fasting glucose metabolism. Nature 437: 1109-1111.

Korswagen, H. C., J. H. Park, Y. Ohshima and R. H. Plasterk, 1997 An activating mutation in a Caenorhabditis elegans Gs protein induces neural degeneration. Genes Dev 11: 1493-1503.

Korswagen, H. C., A. M. van der Linden and R. H. Plasterk, 1998 G protein hyperactivation of the Caenorhabditis elegans adenylyl cyclase SGS-1 induces neuronal degeneration. EMBO J 17: 5059-5065.

Lanjuin, A., and P. Sengupta, 2002 Regulation of chemosensory receptor expression and sensory signaling by the KIN-29 Ser/Thr kinase. Neuron 33: 369-381.

Maduzia, L. L., A. F. Roberts, H. Wang, X. Lin, L. J. Chin et al., 2005 C. elegans serine-threonine kinase KIN-29 modulates TGFbeta signaling and regulates body size formation. BMC Dev Biol 5: 8 .

Manser, J., and W. B. Wood, 1990 Mutations affecting embryonic cell migrations in Caenorhabditis elegans. Dev Genet 11: 49-64.

Mayer, M. G., C. Rodelsperger, H. Witte, M. Riebesell and R. J. Sommer, 2015 The Orphan Gene dauerless Regulates Dauer Development and Intraspecific Competition in Nematodes by Copy Number Variation. PLoS Genet 11: e1005146.

Mello, C. C., J. M. Kramer, D. Stinchcomb and V. Ambros, 1991 Efficient gene transfer in C.elegans: extrachromosomal maintenance and integration of transforming sequences. Embo J 10: 3959-3970.

Miska, E. A., C. Karlsson, E. Langley, S. J. Nielsen, J. Pines et al., 1999 HDAC4 deacetylase associates with and represses the MEF2 transcription factor. EMBO J 18: 5099-5107.

Moorman, C., and R. H. Plasterk, 2002 Functional characterization of the adenylyl cyclase gene sgs-1 by analysis of a mutational spectrum in Caenorhabditis elegans. Genetics 161: 133-142.

Okamoto, M., H. Takemori and Y. Katoh, 2004 Salt-inducible kinase in steroidogenesis and adipogenesis. Trends Endocrinol Metab 15: 21-26. 
Pavelec, D. M., J. Lachowiec, T. F. Duchaine, H. E. Smith and S. Kennedy, 2009 Requirement for the ERI/DICER complex in endogenous RNA interference and sperm development in Caenorhabditis elegans. Genetics 183: 1283-1295.

Phelan, P., J. P. Bacon, J. A. Davies, L. A. Stebbings, M. G. Todman et al., 1998 Innexins: a family of invertebrate gap-junction proteins. Trends Genet 14: 348-349.

Qadota, H., M. Inoue, T. Hikita, M. Koppen, J. D. Hardin et al., 2007 Establishment of a tissue-specific RNAi system in C. elegans. Gene 400: 166-173.

Rual, J. F., J. Ceron, J. Koreth, T. Hao, A. S. Nicot et al., 2004 Toward improving Caenorhabditis elegans phenome mapping with an ORFeome-based RNAi library. Genome Res 14: 2162-2168.

Sandberg, M., E. Butt, C. Nolte, L. Fischer, M. Halbrugge et al., 1991 Characterization of Sp-5,6-dichloro-1-beta-D-ribofuranosylbenzimidazole3',5'-monophosphorothioate (Sp-5,6-DCl-cBiMPS) as a potent and specific activator of cyclic-AMP-dependent protein kinase in cell extracts and intact cells. Biochem J 279 ( Pt 2): 521-527.

Schade, M. A., N. K. Reynolds, C. M. Dollins and K. G. Miller, 2005 Mutations that rescue the paralysis of Caenorhabditis elegans ric-8 (synembryn) mutants activate the $\mathrm{G}$ alpha(s) pathway and define a third major branch of the synaptic signaling network. Genetics 169: 631-649.

Simmer, F., C. Moorman, A. M. van der Linden, E. Kuijk, P. V. van den Berghe et $a l ., 2003$ Genome-wide RNAi of C. elegans using the hypersensitive rrf-3 strain reveals novel gene functions. PLoS Biol 1: E12.

Starich, T., M. Sheehan, J. Jadrich and J. Shaw, 2001 Innexins in C. elegans. Cell Commun Adhes 8: 311-314.

Stefanakis, N., I. Carrera and O. Hobert, 2015 Regulatory Logic of Pan-Neuronal Gene Expression in C. elegans. Neuron 87: 733-750.

Sulston, J. E., 1983 Neuronal cell lineages in the nematode Caenorhabditis elegans. Cold Spring Harb Symp Quant Biol 48 Pt 2: 443-452.

Sunahara, R. K., C. W. Dessauer and A. G. Gilman, 1996 Complexity and diversity of mammalian adenylyl cyclases. Annu Rev Pharmacol Toxicol 36: 461-480.

Svendsen, P. C., and J. D. McGhee, 1995 The C. elegans neuronally expressed homeobox gene ceh-10 is closely related to genes expressed in the vertebrate eye. Development 121: 1253-1262.

Takemori, H., Y. Katoh, N. Horike, J. Doi and M. Okamoto, 2002 ACTH-induced nucleocytoplasmic translocation of salt-inducible kinase. Implication in the protein kinase A-activated gene transcription in mouse adrenocortical tumor cells. J Biol Chem 277: 42334-42343.

Timmons, L., D. L. Court and A. Fire, 2001 Ingestion of bacterially expressed dsRNAs can produce specific and potent genetic interference in Caenorhabditis elegans. Gene 263: 103-112.

van der Linden, A. M., K. M. Nolan and P. Sengupta, 2007 KIN-29 SIK regulates chemoreceptor gene expression via an MEF2 transcription factor and a class II HDAC. EMBO J 26: 358-370.

van der Linden, A. M., S. Wiener, Y. J. You, K. Kim, L. Avery et al., 2008 The EGL4 PKG acts with KIN-29 salt-inducible kinase and protein kinase A to regulate chemoreceptor gene expression and sensory behaviors in Caenorhabditis elegans. Genetics 180: 1475-1491. 
Vatner, D. E., L. Yan, L. Lai, C. Yuan, L. Mouchiroud et al., 2015 Type 5 adenylyl cyclase disruption leads to enhanced exercise performance. Aging Cell 14: 1075-1084.

Wang, B., J. Goode, J. Best, J. Meltzer, P. E. Schilman et al., 2008 The insulinregulated CREB coactivator TORC promotes stress resistance in Drosophila. Cell Metab 7: 434-444.

Wang, B. B., M. M. Muller-Immergluck, J. Austin, N. T. Robinson, A. Chisholm et al., 1993 A homeotic gene cluster patterns the anteroposterior body axis of C. elegans. Cell 74: 29-42.

Wang, Z., H. Takemori, S. K. Halder, Y. Nonaka and M. Okamoto, 1999 Cloning of a novel kinase (SIK) of the SNF1/AMPK family from high salt diet-treated rat adrenal. FEBS Lett 453: 135-139.

Wenick, A. S., and O. Hobert, 2004 Genomic cis-regulatory architecture and transacting regulators of a single interneuron-specific gene battery in C. elegans. Dev Cell 6: 757-770.

White, J. G., E. Southgate, J. N. Thomson and S. Brenner, 1976 The structure of the ventral nerve cord of Caenorhabditis elegans. Philos Trans R Soc Lond B Biol Sci 275: 327-348.

White, J. G., E. Southgate, J. N. Thomson and S. Brenner, 1986 The structure of the nervous system of the nematode Caenorhabditis elegans. Philos Trans R Soc Lond B Biol Sci 314: 1-340.

Wicks, S. R., R. T. Yeh, W. R. Gish, R. H. Waterston and R. H. Plasterk, 2001 Rapid gene mapping in Caenorhabditis elegans using a high density polymorphism map. Nat Genet 28: 160-164.

Wightman, B., S. G. Clark, A. M. Taskar, W. C. Forrester, A. V. Maricq et al., 1996 The C. elegans gene vab- 8 guides posteriorly directed axon outgrowth and cell migration. Development 122: 671-682.

Wolf, F. W., M. S. Hung, B. Wightman, J. Way and G. Garriga, 1998 vab-8 is a key regulator of posteriorly directed migrations in C. elegans and encodes a novel protein with kinesin motor similarity. Neuron 20: 655-666.

Wu, Y., A. Ghitani, R. Christensen, A. Santella, Z. Du et al., 2011 Inverted selective plane illumination microscopy (iSPIM) enables coupled cell identity lineaging and neurodevelopmental imaging in Caenorhabditis elegans. Proc Natl Acad Sci U S A 108: 17708-17713.

Zinovyeva, A. Y., and W. C. Forrester, 2005 The C. elegans Frizzled CFZ-2 is required for cell migration and interacts with multiple Wnt signaling pathways. Dev Biol 285: 447-461. 


\section{Figures}
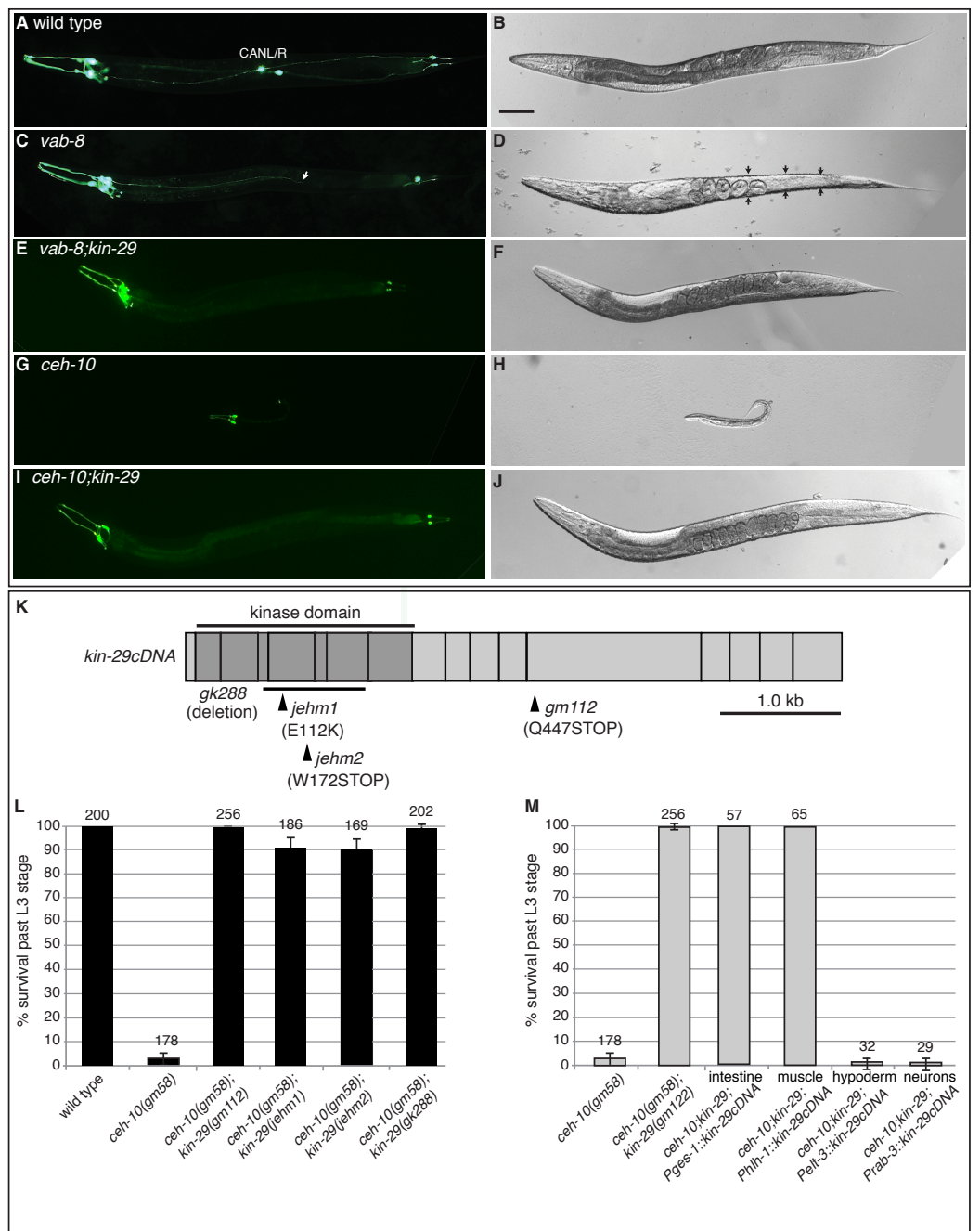

853 Figure 1 Mutations in kin-29 rescue phenotypes caused by defective CANs.

854 (A, C, E, G ) Fluorescence photomicrographs and (B, D, F, I) Nomarski

855 microscopy of worms containing the Pceh-23::GFP transgene, which is

856 expressed in the CANs and in tail and head neurons. (A-J) Anterior is to the

857 left and dorsal is up, the scale bar represents $100 \mu \mathrm{m}$. (A) In wild-type worms,

858 the CAN cell bodies are located in the middle of the worm and each neuron

859 extends axons both anteriorly and posteriorly. (B) The body morphology of a

860 wild-type worm. (C) In vab-8 mutants, the CANs fail to migrate and are

861 located in the head among the other neurons that express GFP. The CAN 
862

863

864

865

866

867

868

869

870

871 were identified based on the presence of the co-transforming marker.

axons fail to extend to the tail (the arrowhead indicates where one of the axon's projection stops). (D) The posterior body, as indicated by the arrows, is much thinner in vab-8 mutants (the Withered Tail or Wit phenotype). (E) In vab-8; kin-29 double mutants, the CAN migration and extension defects are not rescued, (F) but the Wit phenotype is rescued. $(G)$ In ceh-10 mutants, the CANs fail to express Pceh-23::GFP. (H) ceh-10 mutants arrest their development during the L1-L2 larval stage. (I) In ceh-10; kin-29 double mutants, the CANs still are undetectable, $(\mathrm{J})$ but the larval arrest is rescued. (K) The structure of kin-29 cDNA and the different mutant alleles used in this study. ( $L$ and M) Quantification of survival past the L3 larval stage. The number of animals scored for each genotype is indicated above each bar. Error bars show the $95 \%$ confidence interval determined by Z-tests. (L) kin-29 mutant alleles rescue the larval arrest phenotype of ceh-10 mutants. (M) Tissue-specific expression of kin-29 cDNA in ceh-10; kin-29 mutants. kin-29 cDNA was expressed from an intestinal specific (Pges-1), a body wall muscle specific (Ph/h-1), a hypodermal specific (Pelt-3) and a pan-neuronal promoter (Prab-3). The number of animals for ceh-10; kin-29; Pelt-3::kin-29 and ceh-10; kin-29; Prab-3::kin-29 were small because these animals arrested development and could not be propagated. The arrested transgenic animals 882 


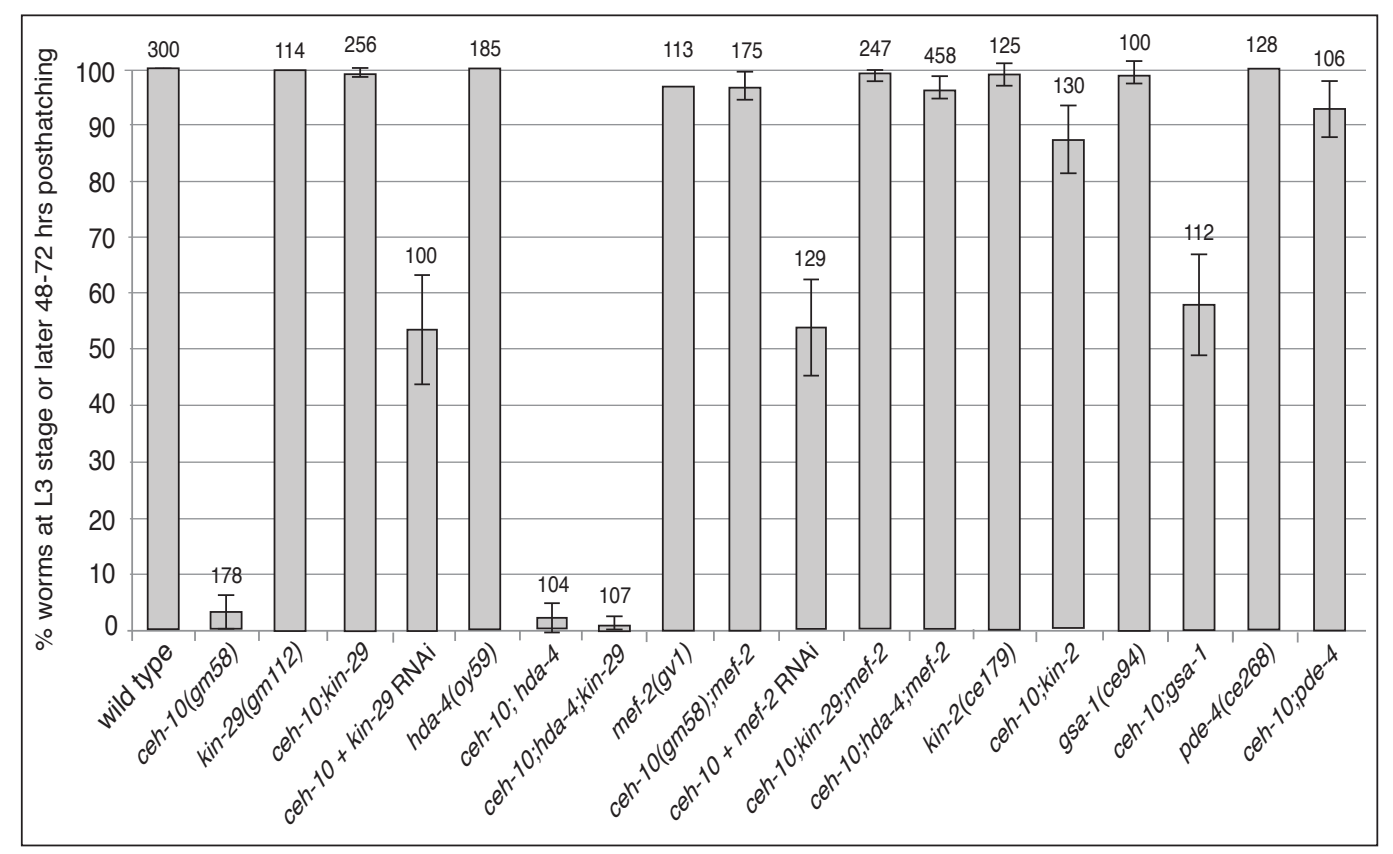

884

885 Figure 2 Mutations that upregulate cAMP levels and PKA activity and reduce

886 the function transcription factor MEF-2 rescue the ceh-10 mutant larval arrest

887 phenotype. Quantification of survival past the L3 larval stage of wild type,

888 single, double and triple mutant strains containing the ceh-10 mutation. The

889 number of animals scored for each genotype is indicated above each bar.

890 Error bars show the 95\% confidence interval determined by Z-tests. 


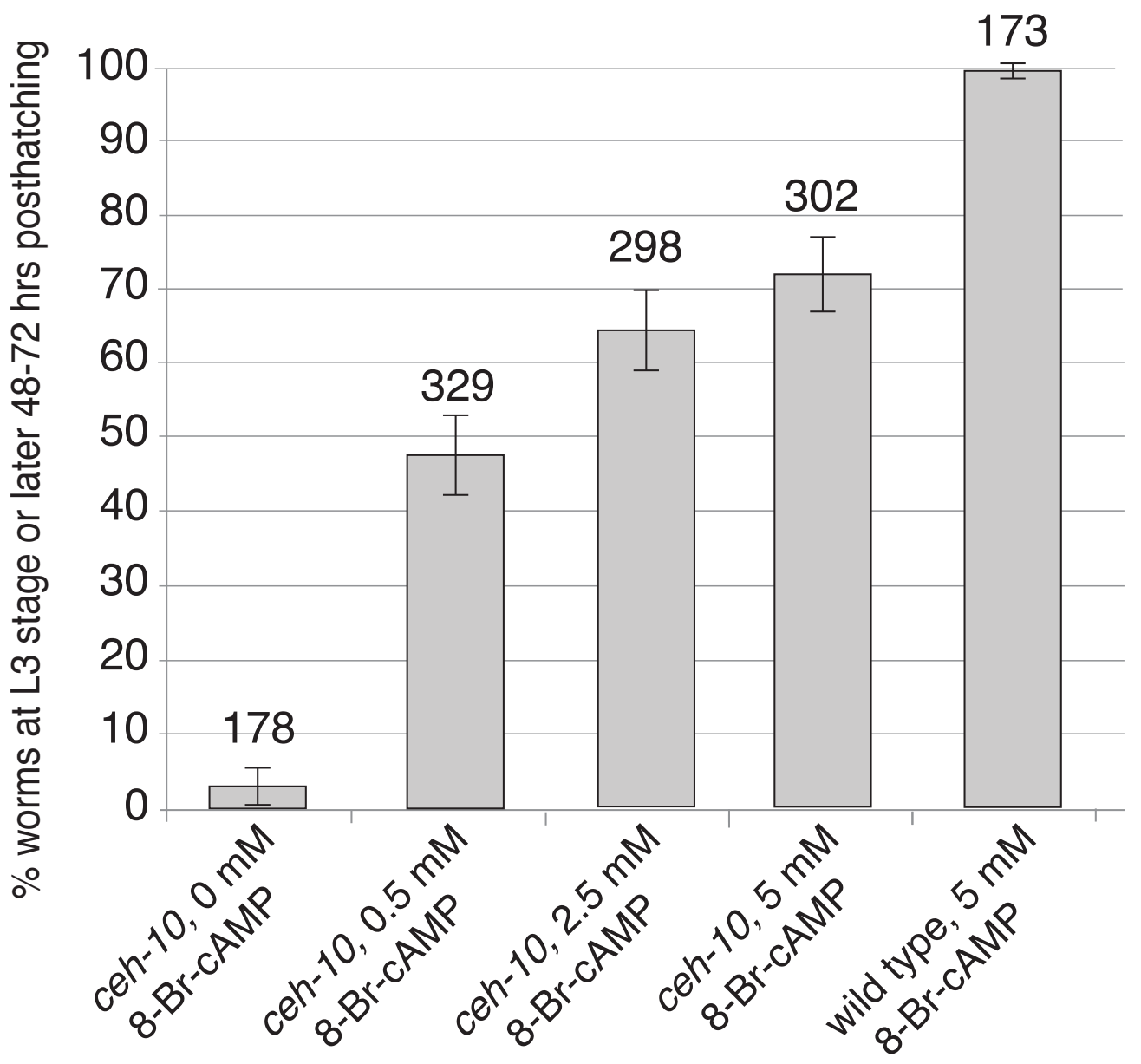

894 Figure 3 Feeding ceh-10 mutants synthetic cAMP rescues the larval arrest

895 phenotype. Quantification of survival past the L3 larval stage of ceh-10

896 mutants grown on normal plates seeded with bacteria mixed with different

897 concentrations of 8-Br-cAMP. The number of animals scored for each

898 genotype is indicated above each bar. Error bars show the $95 \%$ confidence

899 interval determined by Z-tests.

900 

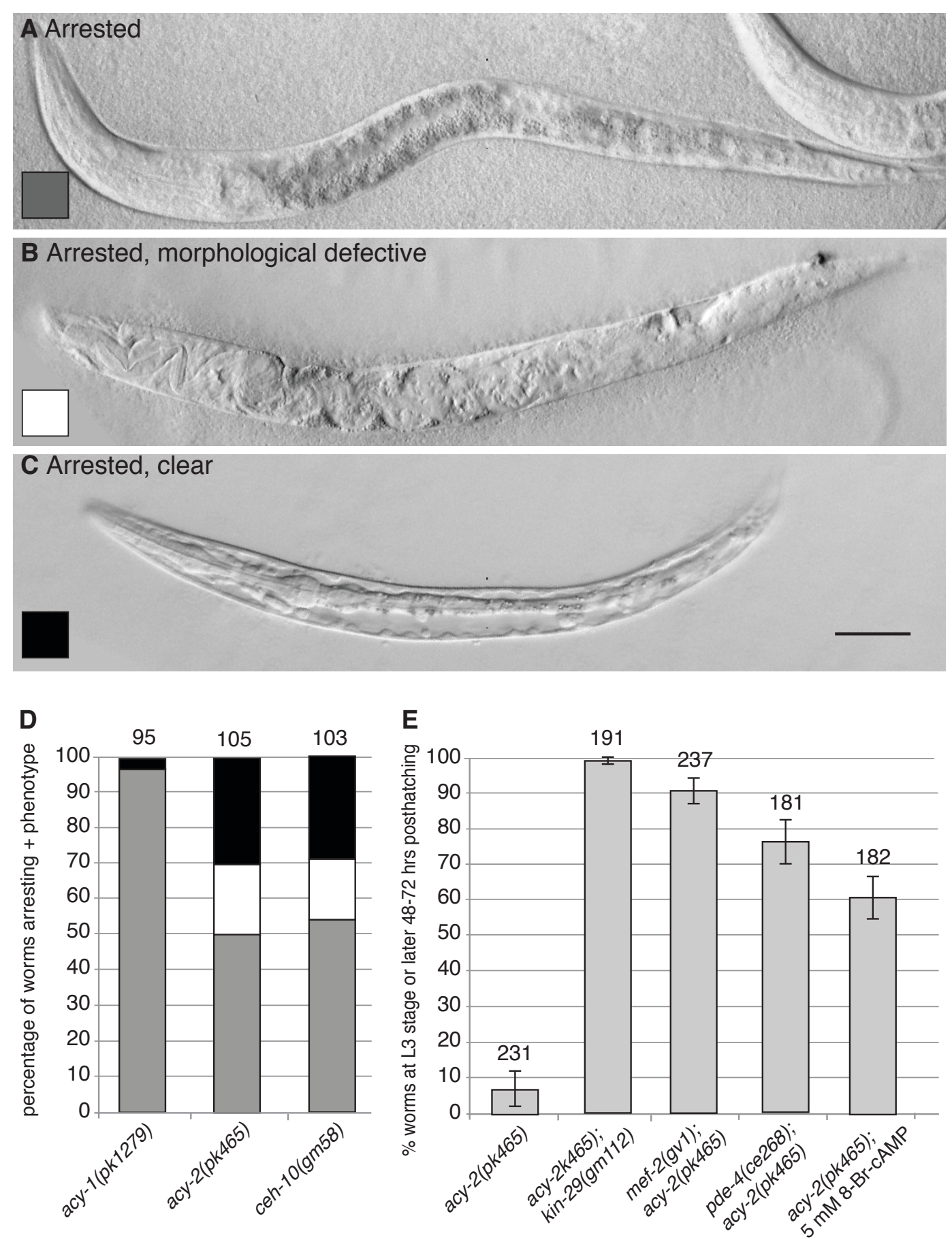

903 Figure 4 The kin-29 and acy-2 mutants have similar phenotypes. (A) An

904 arrested ceh-10 larva with normal body morphology. The arrowheads mark

905 the width of the intestine. (B) A ceh-10 mutant with a morphological defective 
906 body in which the internal cells appear abnormal. (C) An arrested ceh-10

907 mutant with a Clr phenotype. Note that the intestine is much thinner compared

908 to the intestine in the worm in A) (see arrowheads). (D) Quantification of acy-

$9091, a c y-2$ and ceh-10 mutants that arrest either with a normal body, a

910 morphological defective body or with a Clr phenotype. (E) Quantification of

911 survival past the L3 larval stage of acy-2 single mutants, acy-2; kin-29, mef-2;

912 acy-2 and pde-4; acy-2 double mutants and acy-2 mutants fed with $5 \mathrm{mM}$ 8-

$913 \mathrm{Br}$-cAMP. The number of animals scored for each genotype in $\mathrm{E}$ is indicated

914 above each bar.

915

916 

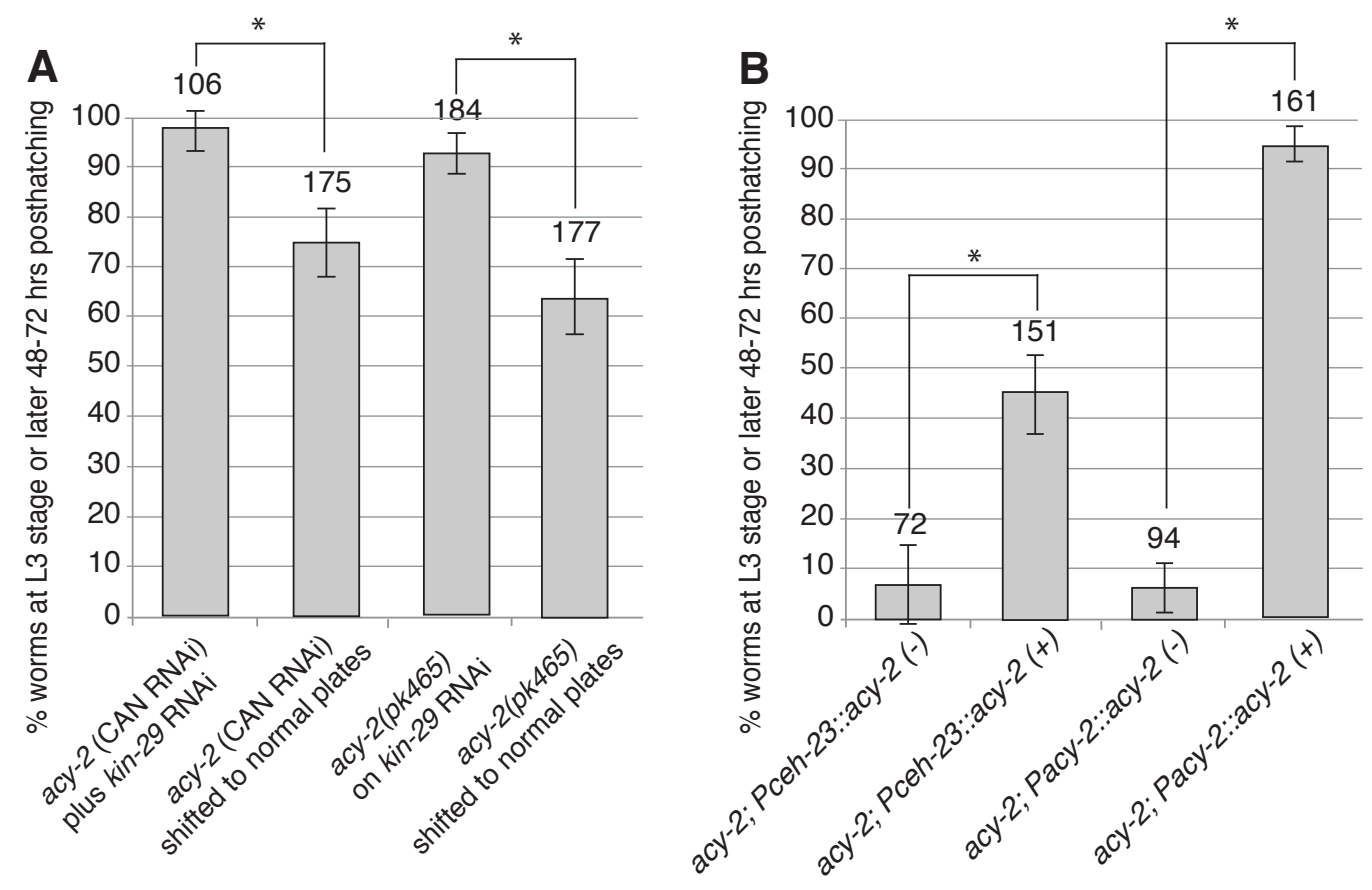

918 Figure 5 Larval development requires acy-2 function in the CANs. (A)

919 Quantification of survival past the L3 larval stage of acy-2 mutant worms or

920 wild-type worms carrying transgenes that express acy-2 dsRNA specifically in

921 the CANs (acy-2(CAN RNAi)). The worms were initially grown on bacteria that

922 produce kin-29 dsRNA (kin-29 RNAi) and then transferred to plates with

923 bacteria that do not express kin-29 dsRNA. (B) Quantification of survival past

924 the L3 larval stage of acy-2 mutant worms either lacking or carrying the

925 extrachromosomal PCAN::acy-2 transgene that expresses acy-2 specifically

926 in the CANs (2 lines). As control ACY-2 was expressed from its endogenous

927 promoter. The number of animals scored for each genotype in E-G is

928 indicated above each bar. Error bars show the 95\% confidence interval

929 determined by Z-tests. *: $p<0.0001$ (Fisher's exact test) 


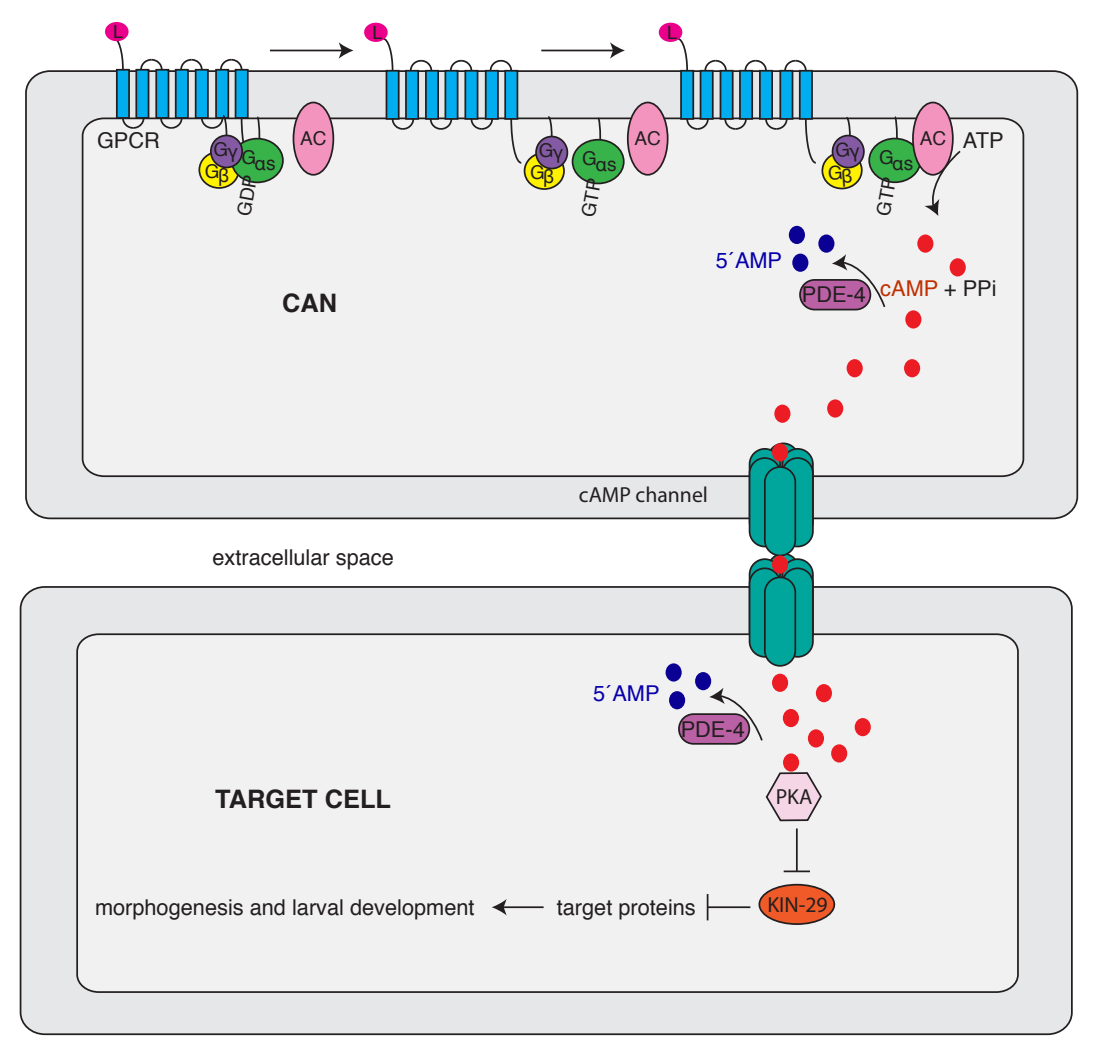

931 Figure 6 A model for CAN function in larval development. The model

932 proposes that the CANs produce cAMP that diffuses into target hypodermal

933 and neuronal cells where the PKA pathway is activated. A ligand $(L)$ binds to

934 a G protein-coupled receptor (GPCR) located in the cell membrane of the

935 CAN neuron. The GPCR activates the G protein that can in turn activate

936 adenylyl cyclase (AC). AC converts ATP into cAMP that diffuses via cAMP-

937 permeable channels into a target cell. In the target cell cAMP binds to the

938 regulatory subunits of protein kinase $A(P K A)$ that allows dissociation of the

939 catalytic subunits, which then can phosphorylate and inhibit the

940 serine/threonine kinase KIN-29. When KIN-29 is inhibited, KIN-29 target

941 proteins are activated to promote morphogenesis and survival. The levels of

942 cAMP are regulated by phosphodiesterases, for example PDE-4 that

943 degrades cAMP to 5'AMP. 
946 TABLE 1 C. ELEGANS ADENYLYL CYCLASES

947

\begin{tabular}{llll} 
GENE & HOMOLOG & EXPRESSION & PHENOTYPE \\
\hline acy-1 & AC9 & neurons in head and tail ganglia, & larval arrest, \\
& & ventral nerve cord, weak in CANs, & paralysis (MOORMAN \\
& & vulva and body wall muscles & AND PLASTERK 2002) \\
\hline acy-2 & AC2 & few neurons in head ganglia and & larval arrest, clear \\
& & ventral nerve cord, strong expression & (KORSWAGEN et al. \\
& & in CANs & 1998) \\
\hline acy-3 & AC5 & support cells of ciliated neurons, & reduced fat content \\
& & head and tail ganglia, two pairs of & (AsHRAFI et al. \\
& neurons in the retrovesicular ganglia, & 2003), improved \\
& spermatheca & mitochondrial \\
& & function, antioxidant \\
& & defence and lifespan \\
& & & (VATNER et al. 2015) \\
& & & sterile adults \\
& & & (GovinDAN et al. \\
& & &
\end{tabular}

